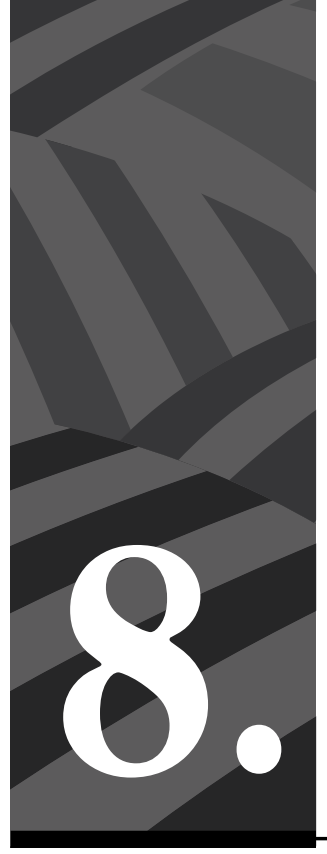

El rol de las comunidades campesinas de El Pato (Caquetá) en la implementación del punto dos del Acuerdo Final de Paz de La Habana, en momentos de incertidumbre nacional 


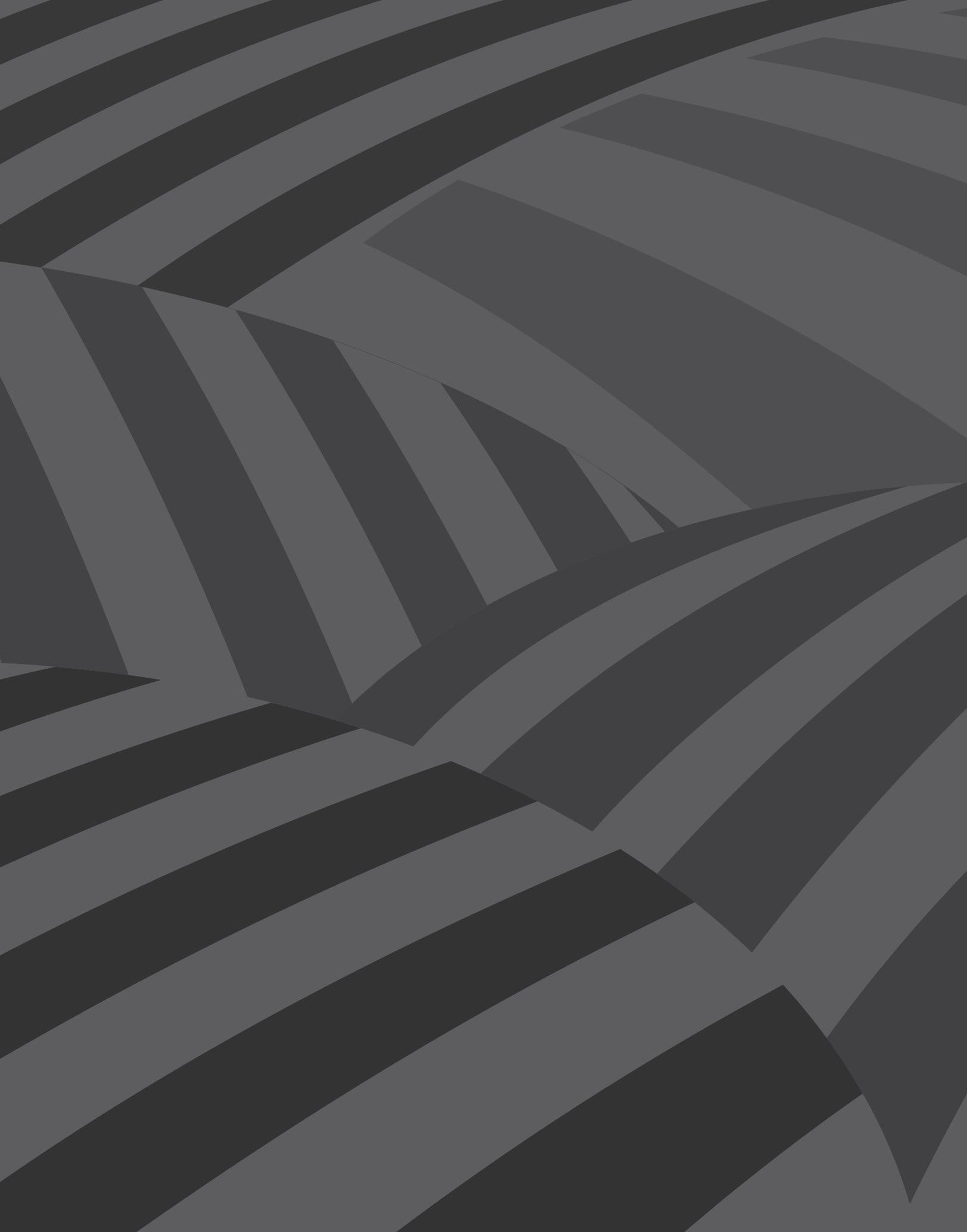




\section{El rol de las comunidades campesinas de El Pato (Caquetá) en la implementación del punto dos del Acuerdo Final de Paz de La Habana, en momentos de incertidumbre nacional*}

Por Juano Zuluaga García**

DOI: https://doi.org/10.54118/controver.vi217.1241

Resumen: La implementación del Acuerdo Final de Paz ha tenido sus avances y retrocesos. Por un lado, el panorama nacional es alarmante: se evidencian altos picos de violencia política; reconfiguración de actores armados; asesinato sistemático de líderes sociales, reincorporados, etc.; la implementación real de lo acordado es mínima; y hace falta mayor voluntad y efectividad del Estado colombiano y del Gobierno nacional. En contraste, no se pueden desconocer las dinámicas de apropiación y organización social ni el rol transformador de las comunidades desde los territorios. El presente trabajo tiene como propósito poner en diálogo una reflexión crítica de la situación nacional del punto dos del Acuerdo con los procesos impulsados por las comunidades de El Pato (Caquetá), y la forma en que estas vienen tejiendo una cultura política participativa y pluralista, aportando así a la implementación del punto dos en, con, desde y para el territorio.

Palabras clave: Acuerdo Final de Paz, democracia, democratización, pluralismo, comunidades campesinas, unidad, organización, movilización, transformación, líderes sociales, cultura política, radicalización de la democracia.

* $\quad$ El presente artículo es una reflexión derivada de la investigación: «"Organizaciones campesinas en movimiento”: semillas de resistencia y lucha colectiva en El Pato (Caquetá) por otros mundos posibles (1921-2020)», realizada por el autor, la cual obtuvo el reconocimiento de Tesis Laureada por parte del Consejo Académico de la Universidad Surcolombiana. A propósito: un agradecimiento especial a Marco Antonio Ceballos, quien, en calidad de tutor, acompañó dicho proceso.

* Politólogo de la Universidad Surcolombiana, director e investigador del Centro de Investigación e Inter-acción Social del Sur Colombiano (Ceiinso), miembro de la Unidad Investigativa del Portal La Gaitana e integrante de la Corporación Jurídica y Derechos Humanos Semilla y Memoria. Correo electrónico: juano.zuluaga@ hotmail. com y juano.ceiinso@gmail.com - ORCID: 0000-0002-5179-2875 


\section{The Role of the Peasant Communities of El Pato (Caquetá) in the Implementation of Point Two of the Final Peace Agreement of Havana, in Times of National Uncertainty}

Abstract: The implementation of the Final Peace Agreement has had progress and setbacks. On the one hand, the national panorama is alarming: high peaks of political violence are evident. Reconfiguration of armed actors; systematic murder of social leaders, reincorporated, etc. The actual implementation of the agreement is minimal; and greater will and effectiveness of the Colombian State and the national government are needed. In contrast, the dynamics of appropriation and social organization and the transforming role of the communities from the territories cannot be ignored. The purpose of this paper is to put into dialogue a critical reflection of the national situation of point two of the Agreement with the processes promoted by the communities of El Pato (Caquetá). Also, the way in which they have been weaving a participatory political culture and pluralist. Thus, contributing to the implementation of point two in, with, from and for the territory.

Keywords: Final Peace Agreement, democracy, democratization, pluralism, peasant communities, unity, organization, mobilization, transformation, social leaders, political culture, radicalization of democracy.

Cómo citar este artículo: Zuluaga García, Juano. El rol de las comunidades campesinas de El Pato (Caquetá) en la implementación del punto dos del Acuerdo Final de Paz de La Habana, en momentos de incertidumbre nacional. Revista Controversia, 217, 301-335.

Fecha de recepción: 28 de febrero de 2021

Fecha de aprobación: 21 de mayo de 2021

\section{Introducción}

1 Acuerdo Final para la Terminación del Conflicto y la Construc-
ción de una Paz Estable y Duradera (en adelante Acuerdo Final de
Paz, Acuerdo de Paz o Acuerdo), generó ciertos niveles de expectativa y, a su vez, de incertidumbre en diversas zonas rurales del país que históricamente han tenido presencia e incidencia directa de actores armados, y a raíz de ello han sufrido los embates de la guerra. Esto tiene un agravante: el incumplimiento de lo pactado en experiencias previas 
de negociación, en las que el anhelo de construcción de una paz con justicia social y transformaciones sociopolíticas se disipó. A continuación, se mencionan cuatro casos al respecto.

El primero es el proceso con Rojas Pinilla (1953-1958), que se limitó al desarme y la rendición, al posterior asesinato de líderes guerrilleros firmantes — como fue el caso de Guadalupe Salcedo (Molano, 2015, p. 562) - , al contexto de violencia política nacional y la imposición del Frente Nacional (1958-1974).

El segundo es el acuerdo de La Uribe (Meta), en el gobierno de Belisario Betancur (1982-1986), producto del cual se fundó la Unión Patriótica (UP). La creación de este partido tenía como propósito garantizar el robustecimiento de la democracia y la participación política de otros actores colectivos, más allá del bipartidismo, característica del sistema político colombiano. La UP representó una importante opción de poder: llegó a ganar varios concejos y alcaldías municipales, entre otros espacios, desafiando así a la derecha, lo cual coincidió con una incontrolable dinámica de protesta social (Molano, 2015, p. 590). A raíz de esto se presentó el genocidio contra la UP, en el cual, a partir de la lucha histórica impulsada por los familiares de las víctimas, se ha venido evidenciando la responsabilidad del Estado, sus aparatos de seguridad y de los grupos paramilitares, entre otros.

Tercero, en el gobierno de César Gaviria se adelantaron diálogos con la Coordinadora Guerrillera Simón Bolívar ${ }^{1}$, conformada por el Movimiento 19 de Abril (M-19), el Ejército de Liberación Nacional (ELN), el Ejército Popular de Liberación (EPL), el Movimiento Quintín Lame, el Partido Revolucionario de los Trabajadores (PRT) y las Fuerzas Armadas Revolucionarias de Colombia-Ejército del Pueblo (FARC-EP); sin

1 Cabe precisar que se realizaron varios intentos de diálogo, por ejemplo, en Venezuela y Tlaxcala, México, en 1992, pero no se logró consolidar un proceso general. 
embargo, solo se logró un acuerdo con el M-19, el PRT y el Movimiento Quintín Lame, en gran medida por la falta de confianza en el Gobierno y en el establecimiento - que se vio confirmada con el bombardeo a Casa Verde, sede del secretariado de las FARC, hecho ocurrido el 9 de diciembre de 1990, día de las elecciones para la Constituyente (Zubiría, 2015, p. 44)—, así como en la apertura económica.

Sin embargo, cabe destacar como un logro de este proceso la elección de la Asamblea Nacional Constituyente que redactó la Constitución Política de 1991, producto, en gran medida, de estas conversaciones de paz, de la dinámica de la Séptima Papeleta (Fals, 1991) y los intereses por modernizar el país. No obstante, varios líderes del M-19 fueron asesinados, se profundizó el neoliberalismo y se han venido realizando una serie de reformas constitucionales en contravía del espíritu democratizador de la Constitución de 1991.

Cuarto, las negociaciones entre las FARC-EP y el gobierno de Andrés Pastrana en la llamada Zona de Despeje, que no tuvo un feliz término; por el contrario, tras la ruptura se anunció el Plan Colombia y con este la prolongación de la guerra, que fue secundada por los dos mandatos presidenciales de Álvaro Uribe Vélez (2002-2006 y 2006-2010), según Carrillo (2016, pp. 133, 145).

Lo anterior explica los niveles de expectativa durante las negociaciones de paz de La Habana (Cuba), especialmente en zonas rurales que han estado azotadas por el conflicto político, social y armado, y que veían en estas una oportunidad significativa para la solución de problemas históricos, para ampliar la participación e incidencia política en los asuntos locales y del país, para una posible solución al problema de las drogas de uso ilícito, para sentar las bases de una reforma agraria integral, y para brindar auténticas garantías a las víctimas en cuanto a verdad, justicia, reparación y no repetición. 
En ese orden de ideas, y reconociendo un panorama nacional y territorial complejo, pero rodeado de oportunidades y potencialidades, con luces y sombras, es importante resaltar un conjunto de procesos que emanan de las comunidades con una fuerza transformadora, que, en últimas, constituyen el faro que ilumina un camino de organización, lucha y resistencia desde los territorios, y unas trayectorias significativas que pueden traducirse en dinámicas de exigencia y apropiación política y cultural del espíritu del Acuerdo.

Es decir, en vista del incumplimiento de lo pactado; del recrudecimiento de la violencia política; de la reconfiguración de actores armados en los territorios; del asesinato de líderes sociales, defensores(as) de derechos humanos y reincorporados(as), las comunidades y distintas organizaciones han dado vida desde abajo, desde los territorios, a importantes procesos y acciones colectivas que representan una fuerza constitutiva de movilización, de radicalización de la democracia y de apropiación de lo pactado, que deberían ser motivo de análisis, visibilización y potenciación en aras de lograr las transformaciones estructurales que demandan la construcción de la paz y la implementación del Acuerdo de Paz.

Estas comunidades han generado las condiciones sociales, políticas y culturales para que en sus territorios se materialice el espíritu democratizador del Acuerdo, y han venido tejiendo procesos no estatales, autogestionados, a través de sus lógicas de unidad y movilización.

En concordancia con este llamamiento, el presente artículo tiene como objetivo identificar la forma en que las organizaciones y comunidades de la Zona de Reserva Campesina (ZRC) de El Pato (Caquetá) vienen aportando a la materialización del punto dos del Acuerdo de Paz "participación política: apertura democrática para construir la paz”. ¿Cómo lograrlo? Poniendo en diálogo su trayectoria y potencial de transformación, organización y capacidad de creación de una cultura política participativa, de cara a un contexto nacional bastante desolador, en el que experiencias como estas constituyen ejemplos de caminos de lucha y construcción de alternativas. 
Esto, en el entendido que, además de ser uno de los territorios más afectados por el conflicto político, social, cultural y ambiental colombiano, El Pato es un baluarte de la organización y lucha del pueblo; es una de las zonas de colonización más relevantes del país; y cuenta con múltiples procesos y prácticas históricas que han contribuido a la cimentación de la democracia, y a tejer una cultura pluralista y agonista de la política. Por tanto, constituye una experiencia significativa que, con avances y retrocesos, con potencialidades y dificultades, representa un faro de lucha desde los territorios, que se ha venido consolidando desde antes del Acuerdo a través de unas trayectorias y unas condiciones sociales, históricas, políticas, sociológicas y culturales, particularmente en lo relacionado con el punto dos y con la construcción de nuevos sujetos, identidades, simbologías, representaciones sociales, disputas por el sentido común, que garantizan las bases político-culturales para una nueva sociedad.

\section{Aproximación conceptual}

En este estudio se parte de asumir el conflicto como elemento constitutivo e inherente a la condición humana, que atraviesa el conjunto de relaciones sociales, y al mismo tiempo, se convierte en una dimensión estructurante del orden social y de las subjetividades que convergen en dicho orden.

Con base en esta perspectiva, es necesario reflexionar sobre las diferentes luchas de la sociedad a partir de "dos nudos problemáticos que, aunque integrados, conviene distinguir analíticamente: la producción de conflictos sociales protagonizados por diferentes agentes y el principio constitutivo de las identidades de los propios sujetos que disputan la conformación del orden” (Retamozo y Stoessel, 2014, p. 20).

Así pues, el permanente estado conflictual de la sociedad es inherente al ser humano y al sentido agonista de la política, en el que se presenta una disputa por la construcción de sentidos e identidades. Por consiguiente, la sociedad en su conjunto debe asumir el conflicto como 
elemento fundante de la realidad social y construir mecanismos para tramitarlos y para abandonar la falsa ilusión hegemonizante de aniquilar el pluralismo social y político. En este orden de ideas, Chantal Mouffe (1999) plantea que:

El objetivo de una política democrática, por tanto, no es erradicar el poder, sino multiplicar los espacios en los que las relaciones de poder estarán abiertas a la contestación democrática. En la proliferación de esos espacios con vistas a la creación de las condiciones de un auténtico pluralismo agonístico. (pp. 24-25).

Siguiendo a Mouffe (1999), se debe construir una cultura política y un pluralismo agonista que no niegue ni mucho menos aniquile la conflictividad; se debe reconocer, por ende, la pluralidad social y política de los distintos actores y sectores que coexisten en la sociedad y aceptarlos como adversarios - no como enemigos-, en el marco de un contexto democrático en el que existe una permanente disputa entre proyectos políticos que se contraponen entre sí en términos de la conducción de la sociedad.

Desde este marco, la construcción de paz debe potenciar los conflictos y radicalizar la democracia a partir de la generación de condiciones plenas para los ejercicios de participación y de fortalecimiento del pluralismo político, buscando que la democratización de la vida social sea uno de los ejes centrales de la consolidación de la paz, asignándole así un sentido crítico a esta.

Es por esto que la etapa de posacuerdo y de construcción de paz puede o no canalizarse en términos de los procesos de trasformación de la sociedad, pues depende del grado de apropiación de los actores sociales, de ahí que la participación política desde abajo, desde las comunidades, desde los oprimidos, sea uno de los epicentros apropiados para la materialización de dicho propósito. Lo anterior tiene relación con lo que plantea Leopoldo Múnera, retomando a Cunill: 
La participación es vista como un elemento prioritario de la democratización, puesto que se busca generar un conjunto de prácticas sociales que produzcan el efecto de 'ampliar la capacidad de influencia sobre el proceso de toma de decisiones en todos los niveles de la actualidad social y de las instituciones sociales'. (1999, p. 9).

\section{Reflexión metodológica}

El presente es un artículo de reflexión derivado de la tesis «"Organizaciones campesinas en movimiento": semillas de resistencia y lucha colectiva en El Pato (Caquetá) por otros mundos posibles (1921-2020)», desarrollada por el autor. Esta fue construida a partir del trabajo de campo, la revisión documental y la triangulación de la información recolectada tanto de corte cualitativo como cuantitativo.

En un primer momento, dicho proyecto se centró en identificar de qué manera las trayectorias, prácticas y procesos políticos promovidos por las organizaciones campesinas de la vereda Los Andes, de El Pato (Caquetá), entre el 2016 y el 2019, han generado condiciones para la implementación del punto sobre participación política del Acuerdo de Paz. Luego, esta se transformó en el desarrollo de la investigación y se tomó parte de la sistematización de la información para la consolidación del presente artículo.

La recolección de la información, además de contar con la revisión documental, estuvo atravesada por el trabajo de campo en el territorio, representado en entrevistas semiestructuradas a distintos líderes de las organizaciones, diarios de campo y la participación en espacios importantes de El Pato; asimismo, el trabajo juvenil desarrollado a partir de la vinculación del colectivo Usco al Territorio (Universidad Surcolombiana), que pese a haber sido intermitente, permitió un mayor acercamiento a las realidades socioterritoriales y un aporte a las apuestas colectivas y procesos de la zona, en concordancia con los postulados 
de la investigación acción participativa y el enfoque crítico, sobre los cuales se cimentó el proceso.

\section{Importancia histórica, retos y dificultades generales de la implementación del punto dos del Acuerdo de Paz}

En términos generales, el espíritu del punto dos $-\mathrm{y}$ si se quiere del conjunto del Acuerdo- es el robustecimiento de la democracia y la creación de garantías plenas de participación de sectores, partidos alternativos y movimientos históricamente excluidos. Esto, con el objetivo de posibilitar espacios de democracia y pluralismo político, y de reconocimiento de las dinámicas de la oposición política ante las medidas adoptadas por el Gobierno nacional y las instancias departamentales y municipales (Gobierno y FARC-EP, 2017, p. 37).

Lo anterior conlleva que, más allá de la eliminación de los conflictos ${ }^{2}$ como algunos sugieren -incluso desde el punto de vista conceptual con la categoría de posconflicto-, se deben potenciar los conflictos y las disputas entre proyectos de sociedad irreconciliables entre sí. Esto implica un conjunto de cambios en el sistema político colombiano y en la cultura política, encaminados a crear una serie de condiciones, a reconocer y a fomentar el pluralismo político.

En este sentido, el punto dos del Acuerdo busca, entre otras cosas: primero, profundizar la democracia en el país, permitiendo la pluralidad política e ideológica (subpunto 2.3.1); segundo, garantías para el ejercicio de la oposición (subpunto 2.1), garantías para los movimientos y organizaciones sociales (subpunto 2.2.1), garantías para los defensores(as) de derechos humanos y líderes sociales (subpunto 2.1.2.2); tercero, garantizar la protesta y la movilización que tengan

2 Al respecto, es menester traer a colación el postulado del filósofo colombiano Estanislao Zuleta: "Solo un pueblo escéptico de la guerra y maduro para el conflicto es un pueblo también maduro para la paz” (citado por Arias, 2015). 
un carácter pacífico (subpunto 2.2.2); cuarto, participación ciudadana a través de medios de comunicación comunitarios (subpunto 2.2.3); quinto, promover el acceso al sistema político (subpunto 2.3.1.1); y sexto, promover la participación electoral (subpunto 2.3.2).

Ahora bien, en el plano de lo real, el panorama resulta más distorsionado, ya que, a modo de ejemplo:

- Primero, en el Congreso se ha dilatado la aprobación de las 16 Circunscripciones Especiales Transitorias de Paz, proyectadas como garantías de participación política para las víctimas y para los territorios más afectados por el conflicto armado (CINEP/PPP-CERAC, 2019, p. 9).

- Segundo, el asesinato sistemático de líderes y defensores(as) de derechos humanos. De hecho, según el informe del Instituto Indepaz, Marcha Patriótica y la Cumbre Agraria, Campesina Étnica y Popular (23 de julio de 2019), desde que se firmó el Acuerdo (noviembre de 2016) hasta julio de 2019, han sido asesinados 623 líderes sociales y defensores de derechos humanos.

- Tercero, después de la firma del Acuerdo, el número de asesinatos de reincorporados es alarmante: según el quinto informe de verificación de la implementación del Acuerdo, realizado por el CINEP y el CERAC (2019, p. 16), la cifra de casos oscilaba entre 85 según la Fiscalía General de la Nación y 90 de acuerdo con datos del Partido FARC. Este dato se ha incrementado exponencialmente, puesto que según Indepaz (citado por teleSURtv, 2021), a febrero de 2021, desde que se firmó el Acuerdo han sido asesinados 258 reincorporados, lo cual va en contravía del punto 2.2.4. "garantías para la reconciliación, la convivencia, la tolerancia y la no estigmatización, especialmente por razón de la acción política y social en el marco de la civilidad" (Gobierno Nacional y FARC-EP, 2016, p. 46), de todo el punto dos -y, si requiere- del espíritu general de lo acordado. 
- Cuarto, según las bases del Plan Nacional de Desarrollo (2018-2022), la inversión destinada a consolidar la paz sería de $\$ 37,1$ billones, focalizados principalmente en los 170 municipios priorizados para los Programas de Desarrollo con Enfoque Territorial (PDET), que equivalen aproximadamente a solo el 3.4\% del total del Plan Plurianual de Inversiones (CINEP-CERAC, 2019, pp. 2-3). El porcentaje de inversión a la construcción de la paz (3.4\%) es irrisoria en comparación con los cerca de $\$ 1.096$ billones previsto en el Plan Plurianual de Inversiones del Plan Nacional de Desarrollo (2018-2022).

Esta situación evidencia que ni la paz ni la implementación del Acuerdo han sido una prioridad en la agenda del Gobierno; además, permite vislumbrar que el Gobierno ha puesto en vilo la ejecución de proyectos encaminados a la materialización del Acuerdo

Estos son solo algunos ejemplos que evidencian la precaria implementación del punto dos. Asimismo, en términos generales, se pueden identificar, entre otros, los siguientes factores:

1. El país asiste a una nueva oleada de violencia política.

2. Los asesinatos no son hechos aislados, puesto que presentan al menos los siguientes patrones de sistematicidad: están dirigidos contra líderes sociales, defensores y defensoras de derechos humanos, reincorporados, líderes comunitarios (principalmente, presidentes de Juntas de Acción Comunal), dirigentes que abanderan procesos de restitución de tierras, el Programa Nacional de Sustitución de Cultivos de uso Ilícito (PNIS) y defensores(as) de los territorios. En suma, no se han creado las condiciones necesarias para garantizar la seguridad de estas personas, como se acordó en el punto 2.1.2.2.

3. Tampoco existen plenas garantías para ejercer la oposición política, el pluralismo y participación en el sistema político y electoral colombiano. 
Pese a la aprobación de la Ley 1909 de 2018 (Estatuto de la Oposición Política), las políticas son muy limitadas, legalistas y minimalistas. Hoy en día, es un riesgo ser de la oposición, adoptar posturas críticas o manifestar inconformismo frente al establecimiento. Al mismo tiempo, siguen existiendo enormes asimetrías de poder, ya que los partidos tradicionales y mayoritarios son los que mantienen el predominio del sistema político; son quienes controlan el Consejo Nacional Electoral, pues las bancadas parlamentarias más fuertes son las que, en últimas, tienen la correlación de fuerzas para nombrar a los magistrados de esta autoridad electoral.

4. Tampoco hay garantías para para la movilización y la protesta social, con lo cual el punto 2.2.2. del Acuerdo no se está cumpliendo. Solo por citar un ejemplo: a raíz del gran paro nacional que se inició el 21 de noviembre de 2019 y se extendió hasta comienzos de 2020, fueron muchos los abusos de autoridad por parte de la fuerza pública.

5. Los medios de comunicación, información y conocimiento siguen, en su gran mayoría, al servicio de la clase política y de los grupos económicos.

Todo esto, y otros factores más que se pueden identificar en un paralelo entre los puntos del Acuerdo y la realidad política nacional, evidencian que el país debe afrontar una serie de retos, en aras de implementar a cabalidad lo pactado y de consolidar una cultura política pluralista; se debe promover una reforma auténtica y amplia del sistema político colombiano; potenciar los niveles de movilización, organización y acción colectiva de los movimientos sociales; y estimular la disputa política para ampliar los canales democráticos que logren sentar las bases para garantizar el espíritu transformador que tiene el Acuerdo.

El Acuerdo de Paz, particularmente el punto dos, cuenta con unos elementos muy potentes en pro de brindar las condiciones para la radicalización de la democracia en el país. Precisamente por esto, algunos 
sectores de la clase política colombiana se han opuesto desde el inicio al proceso de paz y otros no han tenido la suficiente voluntad política para apoyar su implementación, seguramente porque varias de las medidas van en contravía de sus intereses políticos, electorales, económicos y clientelistas. Y esto, sumado a la falta de mayores niveles de movilización social que logren presionar a la clase gobernante, no ha permitido la materialización efectiva de lo pactado.

Empero, el Acuerdo ha tenido cierto impacto en la creación de conciencia colectiva: ha permitido evidenciar fenómenos sociopolíticos que los que conducen la opinión pública y el monopolio de los medios de comunicación habían tratado de maximizar, como la dinámica de la guerra y el problema de las drogas ilícitas, que pese a ser importantes no son ni los únicos flagelos que aquejan a la sociedad colombiana ni los únicos responsables de la situación de pobreza e inequidad que enfrenta el país.

Este panorama, con sus avances y retrocesos, plantea una serie de retos para los territorios y movimientos, en aras de lograr la implementación de lo pactado en el Acuerdo de Paz, como el de constituirse en garantes de su materialización a través de la movilización social y el trabajo comunitario de base, a fin de consolidar una cultura de paz y una cultura política pluralista y agonista. Esta cultura será posible en la medida en que las comunidades se apropien de dicho propósito, ya que es desde las prácticas y procesos sociales, desde las lógicas y dinámicas de participación desde abajo, desde la construcción de sentidos colectivos territorializados y comunalizados que se potencia el nivel político, social, organizativo, deliberativo y simbólico necesarios para tejer una sociedad auténticamente democrática, justa, equitativa y emancipada ante las distintas formas de dominación y opresión.

En este orden de ideas, la experiencia de la zona de reserva campesina El Pato-Balsillas (Caquetá, Colombia) resulta ser un referente importante, 
pues al igual que otras prácticas territoriales constituye una apuesta colectiva de construcción de alternativas, niveles de autonomía, autogestión, participación desde abajo, construcción de memorias colectivas, medios y estrategias comunitarias de comunicación, mecanismos de autoprotección y autorregulación, entre otros, que responden a los desafíos actuales del territorio, la región y el país. Estos avances también tienen sus desafíos internos, por tanto, se identificará la forma en que se ha venido materializando el punto dos del Acuerdo en el territorio, los logros y dificultades, los retos internos y su potencial de organización y movilización articulada, encaminados a exigir el cumplimiento del Acuerdo y por esta vía la democratización del país y los procesos de transformación social.

\section{El Pato-Balsillas: implementación del punto dos en el territorio, retos y potencialidades en un contexto nacional desolador}

La ZRC de El Pato-Balsillas tiene una extensión de 88.401 hectáreas. Se encuentra situada al noroccidente del departamento del Caquetá. Es una de las zonas de colonización campesina y armada más importantes del país. Cuenta con una vasta dinámica de lucha y resistencia: en la década de los 50 arribó al territorio una de las llamadas "columnas en marcha”, proveniente de Villarrica (Tolima); en la década de los 60 fue estigmatizada y catalogada como una "república independiente”, por lo que esta zona fue bombardeada en 1965. Además de ser altamente afectada por el conflicto, ha contado con un campesinado organizado y territorializado, hasta el punto que, como lo relata Gustavo Briñez, desde El Pato salió, en 1980, hacia la ciudad de Neiva, la primera movilización campesina de la etapa contemporánea del país.

\section{Expectativa y percepción de la comunidad patuna frente al Acuerdo de Paz}

Con los acuerdos firmados [el Acuerdo Final de Paz] nosotros hemos estado siempre a la vanguardia; siempre hemos estado ahí luchando para salir 
adelante, teniendo en cuenta que a nosotros nos favoreció bastante, diría yo, porque en la región cesó tanto bombardeo, tanta persecución que nos tenía el ejército y la fuerza pública. (Plácida Perdomo, presidenta Comité de Mujeres de los Andes por la Paz - Compaz, entrevista, 2020).

Sobre la percepción del proceso de paz adelantado en La Habana, es preciso señalar que, inicialmente, la comunidad de El Pato no creyó mucho en este porque previamente habían existido intentos fallidos, como ya se anotó; sin embargo, tras el avance de las negociaciones, el anuncio de un cese al fuego y la firma como tal del Acuerdo de Paz, de cierta forma los campesinos sintieron un desescalonamiento de la guerra y cierta tranquilidad al no estar en medio de los enfrentamientos (Yury Rojas, cofundadora del colectivo Semos de la Loma).

A partir de lo anterior, de las entrevistas a algunos líderes de las organizaciones y de visitas de campo, se pudo inferir que en El Pato los campesinos y campesinas sintieron, por un lado, ciertos niveles de desconfianza y preocupación respecto a la voluntad del Gobierno y del Estado de construir la paz, por un antecedente directo en el territorio a raíz de la Zona de Despeje de la cual hacían parte y de otros procesos de paz fallidos a nivel nacional; y, por otro, creían que podía ser una oportunidad histórica para lograr cierta tranquilidad, ya que como se dijo esta es una de las zonas más afectadas por el conflicto y ha sufrido de manera directa bombardeos, enfrentamientos militares, masacres, desplazamientos y asesinatos.

Además de la tranquilidad en cuanto a ausencia de la violencia directa, la comunidad también ha abrigado expectativas respecto a la visibilización de su territorio, sus procesos, sus necesidades y demandas sociales, así como frente a la presencia del Estado en el sentido de inversión social, y no únicamente con la llegada del aparato militar. Igualmente, veían una oportunidad para acceder a proyectos de cooperación internacional, promoción de apuestas productivas, solución 
al problema agrario y participación política de sus organizaciones, entre otras. En suma, como dijo don Nolberto Villalobos, vicepresidente de la Asociación Municipal de Colonos de El Pato (АMCOP), en entrevista realizada en 2020 y a la cual corresponden este y los apartes que se citarán más adelante:

Consideramos que aquí es tan importante el cumplimiento de estos acuerdos porque encierran y abarcan la mayor parte de los anhelos del pueblo; están reflejados en la paz con justicia social, lo que tiene que ver con la restitución de cultivos de uso ilícito. Los acuerdos, consideramos, son un muy buen documento, solamente falta que el Estado colombiano, que el gobierno cumpla, ¿no?

Tomando como base esta última parte, el incumplimiento del Acuerdo ha dejado en el territorio Jun sinsabor respecto a un proceso histórico de cambio para el conjunto de la sociedad. Esto, muy seguramente, no es solo causa de frustración y de indignación para los habitantes de la ZRC El Pato-Balsillas, sino para diversas comunidades campesinas y distintos sectores de la sociedad colombiana. Sin embargo, como afirmó un líder en proceso de reincorporación del Centro Poblado de Miravalle (en El Pato):

A pesar de la traición del gobierno en la no implementación del Acuerdo, a pesar de que en otros lados nos estén matando, nosotros estamos cumpliendo y queda para la historia que estamos trabajando con la única arma que queremos empuñar: la palabra (comunicación personal ${ }^{3}, 2021$ ).

En el contexto del posacuerdo han llegado a la zona diversas organizaciones con proyectos alternativos, entre ellas: el Proyecto de Memoria Histórica Sur-Versiones en el territorio, la Casa Taller, los proyectos de ecoturismo, las iniciativas que se desarrollaron en la vereda Los Andes

3 Diario de campo, Zuluaga, 2020. 
con la Fundación Picachus y Fondo Lunaria, las actividades productivas del ETCR (piscicultura, huertas, entre otras), según relató Yury Rojas.

No obstante, hoy en día no puede hablarse de una transformación sustancial de las realidades de los campesinos, quienes siguen presentando los mismos problemas y demandas, como lo reiteraron recientemente al gobernador Arnulfo Gasca Trujillo, durante la visita que realizó el 13 de febrero de 2021 al caserío Guayabal: centros de salud, mejoramiento de los colegios, asignación de docentes; programas de vivienda rural, alcantarillado, planta para aguas residuales, instalación de antenas para señal telefónica, programas de emprendimiento y participación para las mujeres y jóvenes; incentivo para productores de café, plátano y frijol; apoyo al ecoturismo y, la principal y más sentida de todas: la pavimentación de la carretera que conduce desde Neiva hasta San Vicente del Caguán, que es una de las necesidades más apremiantes y una reivindicación histórica de la zona (diario de campo, Zuluaga, 2020).

\section{Impactos en materia de representatividad política y procesos electorales: avances y retos en la democratización del país}

\subsection{Plebiscito por la paz: El Pato, sus organizaciones y su compromiso incesante con la paz}

El plebiscito por la paz del año 2016 dejó una frustración muy grande. El mensaje que el país le envió al mundo fue muy vergonzoso. Colombia ha vivido muchas décadas de conflicto armado y el hecho que se haya negado la posibilidad de aprobar el Acuerdo de Paz, incluso por parte de algunas personas que ni siquiera sufrieron las consecuencias del conflicto directamente, no tiene presentación en ninguna parte del mundo. Pese a esto, El Pato y sus organizaciones campesinas lograron hacer el trabajo: socializaron el Acuerdo y hubo un respaldo mayoritario de las comunidades de la zona al plebiscito. Los campesinos patunos entendieron el momento histórico que estaba viviendo Colombia y trabajaron activa y decididamente 
en ese anhelo de conseguir la paz; pero, "queda para la historia que una gran parte de los colombianos no estuvieron a la altura de ese momento tan importante. (Nolberto Villalobos).

Cabe destacar que el papel de las mujeres de la zona en los ejercicios de promoción del voto por la paz, "fue muy importante, tuvo mucha participación; aquí tenemos el valor y el apoyo con esos acontecimientos" (Plácida Perdomo).

\subsection{La participación de las FARC y ciertos cambios en la realidad política nacional: un logro del Acuerdo}

Como fenómeno relevante al respecto y como manifestación social de los impactos de la firma del Acuerdo de Paz, don Nolberto Villalobos destaca:

Ha sido importante que ellos [las FARC], a diferencia de otros momentos y en otras circunstancias, no tengan un fúsil, sino que tengan la palabra para generar conciencia en el pueblo. Si bien el territorio y la comunidad esperaban que después del Acuerdo se produjeran cambios sustanciales en cuanto a la participación política, que permitieran el avance de otras fuerzas excluidas, eso no se ha dado. Aunque se resalta el hecho de que las FARC como movimiento político ${ }^{4}$ puedan participar de los escenarios abiertos para este ejercicio y se hayan presentado con candidatos propios en las pasadas elecciones, en general siguen con los mismos movimientos y partidos políticos tradicionales ${ }^{5}$.

Se hace referencia a la campaña presidencial de Gustavo Petro 2018, ya que esta tuvo lugar con posterioridad a la firma del Acuerdo. Además, desde los procesos sociales se ha visto como la oportunidad más cercana

4 Pasaron de llamarse Fuerza Alternativa Revolucionaria del Común (FARC) a Partido Comunes, como parte de la estrategia político-electoral de cara a los nuevos comicios.

5 Resalta la acogida que tuvo en la región de El Pato la Colombia Humana, encarnada en la figura de Gustavo Petro, en las pasadas elecciones. 
de tener un presidente alternativo, puesto que llegó por primera vez a la segunda vuelta, con un proyecto y una apuesta programática de país que responde a los intereses de las inmensas mayorías; asimismo, su campaña logró unificar a diversos sectores sociales, organizaciones y territorios, y tuvo un impacto muy fuerte en varias zonas rurales del país, entre ellas en El Pato. Este fue un fenómeno político-electoral interesante que se debe tener en cuenta a la hora de hacer un balance crítico del Acuerdo, ya que no solo se configuró después de la firma de este, sino que muchos de los puntos hicieron parte de la agenda programática de los candidatos y sus respectivos sistemas de alianzas, a través de los cuales se consolidaron bloques políticos tanto en favor como en contra.

\subsection{Retos en materia de participación político-electoral}

Los procesos de participación política de la zona después de la firma del Acuerdo no han sido muy diferentes a los que siempre se han desarrollado de manera autogestionada:

Las organizaciones campesinas de El Pato, desde el 2016, han participado en diversos escenarios en los que se ha querido vender la idea de que a las organizaciones y a las comunidades se les están generando las condiciones de participación política, pero realmente no ha sido así. Además, muchas discusiones derivadas del Acuerdo no han trascendido de los foros académicos y otros espacios, incluso se les negó la participación a las víctimas con las 16 Circunscripciones Transitorias Especiales de Paz y aún el país está lejos de una apertura democrática real. (Nolberto Villalobos).

Con relación a lo anterior, guarda gran relevancia el subpunto 2.3.6 del Acuerdo que contempla la promoción de la representación política de la población en las zonas que han sido más afectadas por el conflicto, y está encaminado a promover la participación de las víctimas. Como una estrategia para garantizar este compromiso se plantea la creación de las 
16 Circunscripciones Transitorias Especiales de Paz, para elegir 16 representantes a la Cámara por dos periodos electorales para estos territorios.

Estas aún no han sido aprobadas por el Congreso, dejando así una gran frustración en los territorios que han sido altamente afectados por el conflicto y ven en este mecanismo una forma de hallar solución a muchos de sus problemas, a través de la participación política directa, o por lo menos tener en espacio dónde manifestar su inconformismo:

No nos dan la oportunidad para tener esa participación en el Congreso. El grupo que hay de oposición es muy pequeño, no le permite surgir en medio de toda esta corrupción que hay en el Congreso; entonces, es muy difícil para ellos sacar adelante los proyectos que hay del Acuerdo. (Plácida Perdomo).

Sin embargo, son conscientes de que no es la única salida, y continúan con el fortalecimiento de sus bases socio-organizativas y la movilización como herramientas de participación, aclara don Nolberto Villalobos. Esto resulta muy potente, ya que si bien se desmoronó su aspiración colectiva de participar de las CTEP, dimensionan que la lucha va más allá de la participación electoral y asumen la acción callejera, la organización, la disputa desde la presión social como mecanismos para tramitar sus demandas y lograr las transformaciones que necesita su territorio y el país; esto, sin lugar a dudas, contribuye a la radicalización de la democracia y a la creación de una cultura política participativa y pluralista.

Es decir, las organizaciones que conforman la ZRC de El Pato-Balsillas han participado electoralmente desde antes del Acuerdo, a pesar de la estigmatización, el señalamiento y la desfinanciación, aspecto que no ha cambiado mucho después de este, pues no han contado con apoyo institucional y han tenido que acudir a la mejor herramienta que tienen: la palabra, como instrumento para expresar su inconformidad y dar a conocer sus proyectos e ideas. Sin embargo, las maquinarias electorales del municipio son muy fuertes y hacen más complejo acceder a esos escenarios, según 
comentó don Nolberto Villalobos, quien además señala: la ZRC había tenido su curul en el Concejo Municipal de San Vicente por varios períodos, pero en las pasadas elecciones no lograron unificarse y la perdieron.

A pesar de todos estos avances y retrocesos a escala nacional y territorial, y pese a todo el manto de incertidumbre existente en el país, la ZRC de El Pato-Balsillas es una escuela de democracia que contribuye a la creación de una cultura política alternativa, y que, entre otras cosas, cuenta con una trayectoria importante que le aporta herramientas para dar visibilidad al Acuerdo de Paz, porque, además, entiende que esta es una lucha a largo plazo:

Siempre se ha participado muy incondicional y con mucho optimismo para lograr el desarrollo de nuestra región, buscando ese sentido e ideal de democracia que está muy lejos, pero quisiéramos que llegue el día en que podamos decir "unidos logramos la democracia”. (Plácida Perdomo).

Esto, por un lado, le da paso al siguiente apartado que concierne a la movilización social como herramienta colectiva de transformación; $y$, por otro, es una perspectiva muy poderosa que concibe que solo la lucha a largo plazo, la unidad y la organización, que por décadas han asumido las comunidades campesinas de El Pato, las llevarán a conquistar las garantías para la implementación del Acuerdo y para la democratización del país. Es así como, con una gran convergencia nacional, la sociedad colombiana logrará materializar el espíritu democratizador y transformador que tiene el Acuerdo de Paz.

\section{Movilización social después del Acuerdo de Paz: iescépticos del cumplimiento del Acuerdo, pero optimistas de la fuerza de la lucha social!}

Históricamente las organizaciones de la Zona de Reserva Campesina de El Pato-Balsillas han jugado un rol importante en las jornadas de 
movilización social, lo cual ha sido fundamental no solo para la región, sino para los procesos del país, ya que siempre han participado activa y decididamente en casi todas las convocatorias a marchas y paros, y nadie puede desconocerles ese papel, por el contrario, cuentan con un reconocimiento tanto en el departamento del Caquetá como en el departamento del Huila por su apoyo incondicional, comenta don Nolberto Villalobos.

Pese a que los procesos organizativos de El Pato, sus trayectorias y prácticas han sido muy relevantes tanto para el territorio como para el país, y a pesar de que el Acuerdo ha traído algunas ventajas, no se puede llegar a idealizarlos; hay que reconocer también los retrocesos, las dificultades y los obstáculos que han existido. Esto permite hacer un balance crítico de estos dos procesos y trazar una serie de retos en aras de su fortalecimiento.

En este sentido, se debe reconocer que después de la firma del Acuerdo de Paz la capacidad de movilización de las comunidades campesinas de El Pato ha disminuido tanto en participación como en incidencia, lo cual responde al contexto que está marcando a algunos movimientos del país (Nolberto Villalobos).

No obstante, se espera y se proyecta que esta situación no va durar mucho, y que se avecina un auge de la movilización social:

No podemos bajar la guardia frente a eso, tenemos que estar atentos a todos los movimientos y jugadas políticas y económicas del país para poder dar una respuesta organizada, y ahí seguramente estará la zona de reserva campesina de El Pato. (Nolberto Villalobos).

Posterior al paro nacional agrario, campesino, indígena, afro y popular de 2013, continúa narrando don Nolberto Villalobos, se ha venido hablando de impulsar una gran jornada de movilización a escala nacional; sin embargo, no se ha podido generar dicho proceso. 
No obstante, siguiendo con el relato don Nolberto Villalobos comenta: la ZRC de El Pato-Balsillas ha estado presta a cualquier convocatoria nacional de movilización a través de la Asociación Nacional de las Zonas de Reserva Campesina (ANZOR) ${ }^{6}$; incluso, la situación de confinamiento derivada de la pandemia de la Covid-19, obstaculizó el proceso de articulación y unificación de criterios desde las organizaciones pertenecientes a la ANZORC para convocar a una jornada nacional de movilización en protesta por el incumplimiento del Acuerdo de Paz.

Si bien se ha dado cierta disminución en la capacidad de convocatoria y participación nacional en los procesos de movilización y protesta social por parte de las comunidades campesinas después de la firma del Acuerdo de Paz, no se puede desconocer que han existido importantes jornadas de movilización en las que este sector social ha participado. A su vez, después del Acuerdo de Paz, también han existido sectores que han continuado con sus ejercicios de movilización con mucha fuerza tanto a escala local como nacional; tal es el caso de las jornadas de movilización de los indígenas, las centrales obreras, el auge de la movilización del movimiento estudiantil colombiano, como lo evidenció el gran paro de 2018 liderado por la Unión Nacional de Estudiantes de la Educación Superior (UNEES), y su participación activa y masiva en el paro nacional de finales de 2019 e inicios de 2020, siendo este último uno de los procesos de movilización más fuertes de las últimas décadas; además, en su pliego de exigencias se contemplaba como un punto fundamental el cumplimiento de lo pactado en el Acuerdo de Paz.

A propósito de este escenario de movilización nacional, don Nolberto Villalobos señaló la articulación y participación de las organizaciones y del pueblo patuno, y se refirió a este como:

6 Organización de la cual la AMCOP es una de las asociaciones fundadoras. 
Un apoyo a un pliego, o a un momento que se estaba viviendo a nivel nacional; nosotros participamos, no el gran número que nos habíamos acostumbrado en años anteriores, pero sí hicimos presencia, además, realmente generamos nuevamente en la zona de reserva de la región de El Pato un ambiente para salir a acompañar una gran movilización indefinida a nivel nacional.

\section{Organizaciones después del Acuerdo, dificultades y retos: la autogestión y la unidad como alternativa colectiva}

En términos reales la proyección de que el Acuerdo iba a permitir impulsar, apoyar y fortalecer las organizaciones no ha sido así; no se han logrado materializar las condiciones exigidas respecto a estas y antes, por el contrario, las reglamentaciones que se han expedido recientemente para las entidades y organizaciones sin ánimo de lucro las ha puesto en unas circunstancias complicadas en cuanto a los requisitos para poderse mantener como entes legalmente constituidos, afirma don Nolberto, y continúa explicando las razones: de hecho, hoy en día las organizaciones legalmente constituidas están obligadas a realizar una serie de trámites que antes de la firma del Acuerdo no existían, lo que ha generado que se tengan que enfrentar nuevos mecanismos diferentes a los que previamente estaban acostumbradas. Ahora se exigen mayores requisitos en cuanto a la gestión de recursos y manejo de personal, generándoles algunos contratiempos y dificultades.

No obstante, a pesar de estas dificultades, cabe reconocer que la AMCOP ha logrado mantenerse, gestionar y ejecutar varios proyectos e iniciativas, pero sigue siendo una lógica más complicada que la existente antes del Acuerdo, a la cual ha logrado responder, explica don Nolberto Villalobos. Esta respuesta - dice - se debe a su trayectoria como organización, sin embargo, generan también cierta preocupación para las organizaciones en general las condiciones reales en el marco de la implementación del 
Acuerdo; además, por un conjunto de condiciones endógenas y exógenas, las organizaciones en el caso de El Pato han vivenciado un debilitamiento después de 2016, aunque, debido a su trayectoria, reconocimiento y formación, se han logrado mantener en la arena política.

Lo comentado por don Nolberto indica que, por un lado, se han creado mayores trabas para las organizaciones sociales en cuanto a los requisitos para obtener y mantener su personería jurídica, con la consiguiente incidencia que esto tiene para que puedan acceder a financiación de proyectos y demás ventajas; y, por otro, que ha sido la trayectoria y la dinámica organizativa lo que les ha permitido a la AMCOP y a la ZRC superar las trabas legales y las dificultades que enfrentan actualmente.

Todo esto demuestra que, pese a algunos avances después de la firma del Acuerdo, como el fortalecimiento de la organización y participación de los jóvenes y las mujeres; la llegada de otras organizaciones que han aportado al territorio, como la Red Juvenil Compaz; y el acceso a algunos proyectos, también han surgido nuevas limitantes creadas por el contexto nacional y en ocasiones por la misma institucionalidad. En una etapa en la que se deberían fortalecer las formas organizativas de las comunidades rurales, lo que salta a la vista es la ausencia de los recursos que se esperaban, la disminución y la falta de condiciones reales para la ampliación de la democracia y la participación política en el país.

Aun así, la autogestión, el trabajo de base, la creación de conciencia colectiva, el sentido de unidad, la solidaridad, el trabajo mancomunado y el fortalecimiento de los procesos y las apuestas conjuntas siguen siendo la principal salida al callejón en que ha metido el Gobierno al país en la etapa actual, el cual tiene también una respuesta y una salida desde las comunidades. 


\section{Iniciativas y proyectos comunitarios que contribuyen a la implementación del punto dos del Acuerdo y sus respectivos retos}

\subsection{Construcción de memorias colectivas y apropiación del espacio social}

La apropiación del espacio social, la autorregulación de la vida en comunidad y la construcción de memorias colectivas son pilares fundamentales para la construcción de paz y la realización del Acuerdo desde las comunidades. A continuación, se exponen de manera sucinta algunos procesos y proyectos que desde la ZRC de El Pato-Balsillas se han venido generando de manera comunitaria y que evidencian que en, desde y con los territorios se pueden promover iniciativas que aporten a la materialización de lo pactado en el Acuerdo de Paz y a la transformación de las realidades sociales, políticas, económicas, ecológicas y simbólicas del país.

El Proyecto de Memoria Histórica Sur-Versiones les permitió re-crear de manera participativa y colectiva las narrativas históricas de los sucesos de conflicto armado, los procesos del territorio, el legado de lucha y resistencia, los cuales fueron contados por los mismos colonos. Esto potenció los niveles de identidad hacia el territorio, su historia y las simbologías colectivas que se han tejido por décadas. Asimismo, cabe resaltar que en el territorio, desde hace muchas décadas, se han venido tramando proyectos de memoria colectiva para salvaguardar las narrativas históricas de las comunidades, su afectación por el conflicto y sus procesos de lucha. Este es el caso de los Festivales del Retorno que se celebran todos los años, desde 1984, en el mes de noviembre, en conmemoración de la Marcha de la Vida realizada en 1980 hacia la ciudad de Neiva (Huila), ante la amenaza de un nuevo bombardeo a la zona. 
Desde hace muchas décadas la comunidad ha adoptado formas de regulación de la vida cotidiana: crearon deliberada y participativamente unas Normas Comunitarias de Convivencia, y cada Junta de Acción Comunal (como primera instancia) y la Asociación Municipal de Colonos de El Pato (como segunda instancia) cuenta con unos Comités de Conciliación encargados de tramitar todos los conflictos y las diferentes situaciones de la vida en comunidad. Estos son un mecanismo hibridado de justicia comunitaria muy importante en cuanto a la capacidad de autonomía y de agenciamiento, ante la inoperancia y la falta de garantías de la justicia ordinaria del Estado y el panorama complejo de re-configuración de las conflictividades. Así, es la misma comunidad la que logra dirimir los conflictos y situaciones cotidianas.

La Guardia Campesina es un proyecto que se ha venido impulsado después de la firma del Acuerdo, en aras de generar una respuesta organizada desde las comunidades ante las nuevas necesidades y realidades socioterritoriales. Su propósito es salvaguardar el territorio, el tejido comunitario, la unidad interna y fortalecer el ejercicio que desde hace muchos años vienen realizando los Comités de Conciliación y las Normas Comunitarias de Convivencia en materia de apropiación del espacio social.

\subsection{Casa de la Cultura Huellas de El Pato y la Casa Taller: iniciativas de cultura de paz}

En el marco de la ejecución del Proyecto Memoria Histórica Sur-Versiones, la comunidad de la vereda Balsillas empezó a reunirse y a formular varias propuestas que, más allá de este proyecto, dejaran algo para la zona. Fue así como surgió la idea de construir una Casa de la Cultura para brindar nuevas oportunidades.

La propuesta tuvo gran acogida entre la comunidad, la cual aportó su esfuerzo, unos pocos recursos, una alta dosis de organización y el trabajo arduo de mujeres, hombres, viejos, jóvenes y niños, hasta tener la Casa 
de la Cultura Huellas de El Pato, un espacio que sirve no solo a Balsillas, sino a toda la Zona de Reserva Campesina, al municipio e incluso a nivel nacional, pues según don Nolberto Villalobos, este proyecto:

Ha tenido un impacto muy grande y seguimos insistiendo en que este debe ser el instrumento que ha tenido que afianzarse en nuestro territorio para que le digamos ¡no más! a la guerra, ¡no más! al conflicto. Yo creo que ahí hay una base muy importante y se sigue trabajando a pesar de las dificultades.

La Casa de la Cultura Huellas de El Pato cuenta hoy con un acumulado organizativo interesante, en el que participan más de 90 personas en varias actividades culturales y artísticas, entre ellas el montaje de diversas obras de teatro, ya que el propósito de este proyecto, desde el inicio, ha sido brindar a los jóvenes y niños oportunidades diferentes a las existentes desde años atrás, comenta don Nolberto.

Asimismo, en la vereda Los Andes, la comunidad, a través de la articulación AMcop-Red Juvenil Compaz-Junta de Acción Comunal-colectivo Semos de la Loma, construyó la Casa Taller, una iniciativa hecha realidad gracias a la gestión de recursos de la Red Juvenil Compaz, al proyecto Ambientes para la Paz, a la Junta de Acción Comunal de Los Andes que aportó el lote y a las mingas de trabajo comunitario de la población (Yury Rojas y Albeiro Caro, vicepresidente de la JAC de Los Andes).

Estas y otras iniciativas impulsadas desde la organización campesina, y realizadas mediante el trabajo comunitario, aportan a la reconciliación, la convivencia, la construcción de una cultura de paz y de democracia en el territorio a través del arte y el teatro. Allí, los jóvenes y la comunidad en general han podido dinamizar diversas muestras artísticas y culturales que no solo ofrecen nuevas oportunidades para la población, sino que contribuyen a la creación de conciencia colectiva; a la formación política de nuevas subjetividades, simbologías, representaciones 
e imaginarios colectivos; y a la construcción de una cultura política para la paz, la convivencia, la reconciliación, y la creación de memorias colectivas del conflicto y de la resistencia del pueblo patuno.

\subsection{La emisora comunitaria: una necesidad para la zona de reserva campesina}

Si bien el Acuerdo de Paz incluyó el acceso a mecanismos de difusión, las comunidades campesinas de El Pato no cuentan con una emisora comunitaria propia y tienen que acudir a programas transmitidos por cadenas radiales privadas para visibilizar su territorio, su propia historia, sus intereses y necesidades, revela don Nolberto Villalobos.

Adicionalmente, comenta que cuentan con un medio propio: el periódico El Barcino, que por dificultades de presupuesto enfrenta complicaciones para la impresión y la circulación, y por tal motivo lo han tenido que sacar solamente para fechas especiales, y actualmente tienen el reto de reactivar la circulación. Empero, desde este medio autogestionado han logrado realizar varias apuestas comunicativas para difundir sus ideas, sentires y proyectos comunitarios, tanto en términos de la construcción de la paz como de sus diferentes agendas colectivas.

Desde el colectivo juvenil Semos de la Loma, de manera autogestionada han promovido algunas estrategias comunicativas que han contribuido a la divulgación del contenido del Acuerdo de Paz y su importancia. Tal es el caso de los proyectos Patoneando, Comunicación para la Paz, entre otros. Asimismo, a través de las Escuelas de Formación PopulART han abierto espacios de formación política y promovido una cultura de paz, y el espíritu participativo y de lucha en pro de la transformación del conjunto de la sociedad. 


\section{Conclusiones}

Las causas que originaron y mantienen la situación de conflicto en el país son múltiples y estructurales. Por tanto, el alcance del Acuerdo de Paz va más allá de su firma y apunta a la apertura de canales democráticos para la construcción de una Colombia que pueda, a través del pluralismo político, de la diversidad de posturas, de distintas formas de acción y reflexión, tramitar las diferentes demandas y consolidar su potencial transformador.

La materialización de lo pactado es posible si, y solo si, existe una apropiación del Acuerdo por parte de la sociedad colombiana, y se generan las condiciones objetivas y subjetivas para canalizar el potencial transformador en él previsto. El compromiso de la ciudadanía en general es actualmente más que necesario, urgente, dado el momento de crisis política nacional ocasionada por un Gobierno que se niega a cumplir lo pactado en el Acuerdo, que ha cerrado los canales democráticos, y que no ha tenido una postura radical ni ha tomado medidas contundentes ante el asesinato de líderes sociales, defensores(as) de derechos humanos y reincorporados, en el marco de la nueva ola de violencia que azota al país.

Hoy el Acuerdo, y particularmente el punto dos, atraviesan por un notable incumplimiento. El país, contrario al espíritu democratizador de lo pactado, observa cómo desde la institucionalidad se vienen poniendo una serie de talanqueras que imposibilitan la materialización integral de la "apertura democrática para construir la paz” y la inversión estatal en materia de paz se escatima. Se requiere de mayor efectividad en la veeduría por parte de la comunidad internacional. De igual modo, un fortalecimiento de la disputa política, la movilización y el disentimiento, con la perspectiva de democratizar a Colombia.

Ante estos retos, las comunidades campesinas de El Pato son una escuela de ejercicio democrático por su amplia trayectoria de organización, 
lucha, resistencia, articulación y movilización, y por su potencial para dinamizar y agenciar ideas encaminadas a la exigencia del cumplimiento del Acuerdo, en pro de las transformaciones apremiantes de su territorio y de la sociedad colombiana.

Asimismo, desde sus territorios, sus comunidades -incluso desde antes del Acuerdo- han venido impulsando acciones colectivas que promueven una cultura política participativa, agonista, una conciencia colectiva con capacidad transformadora, con un compromiso con la movilización social que, han posibilitado que en su territorio el espíritu democratizador y pluralista se materialice de cierta forma.

La comunidad de El Pato — al igual que otras del país - está sentida por el incumplimiento del Acuerdo, por la frustración de las transformaciones sociales, políticas, culturales y económicas en sus territorios y la no materialización de sus proyectos productivos. Hoy en día no hay garantías auténticas para que las organizaciones, movimientos y partidos políticos de oposición puedan acceder al sistema político, para ejercer la protesta social, para la participación política plena; sin embargo, de manera autogestionada, desde el campo de lo político, desde la relación conflictual con el establecimiento, tampoco han claudicado en el propósito colectivo de radicalizar la democracia.

En dicho horizonte colectivo, y ante el evidente incumplimiento del Acuerdo de Paz, las comunidades de El Pato tienen claro que la salida es la organización, la unidad y la lucha colectiva. En el caso de generarse este escenario popular estarán presentes no solo para presionar la materialización de los puntos del Acuerdo, sino también para apoyar la construcción de un país auténticamente democrático, equitativo, con justicia social, y para comprometerse con la construcción de nuevos sujetos políticos que contribuyan a la cimentación de otros mundos posibles. 


\section{Referencias}

Arias, Diego. (19 de febrero 2015). 'El diálogo es hoy una necesidad de la humanidad': Estanislao Zuleta. Recuperado de https://www.eltiempo.com/ archivo/documento/CMS-15274538

Barrera, César; Tavares dos Santos, José Vicente; Zuluaga Nieto, Jaime; González Arana, Roberto y González Ortiz, Felipe (Coords.). (2013). Conflictos sociales, luchas sociales y políticas de seguridad ciudadana. México: Universidad Autónoma del Estado der México-Instituto Latinoamericano de Estudios Avanzados de la Universidad de Río Grande del Sol-Consejo Latinoamericano de Ciencias Sociales.

Beltrán, Miguel Ángel. (14 de mayo de 2015). Colombia. Sesenta años de la guerra de Villarrica: un capítulo del terrorismo estatal que "olvidó" el informe "Basta ya". Recuperado de http://elsalmonurbano.blogspot.com/2015/05/ sesenta-anos-de-la-guerra-de-villarrica.html

Briñez, Gustavo. (1998). Historia de la región de El Pato Caquetá, Colombia. Santafé de Bogotá: Trilce Editores.

Carrillo, Sindy Lorena. (2016). "¡Juntos, pero no revueltos!" (O de cómo se ha concertado la regulación social en medio de la guerra) El caso de la región de El Pato. San Vicente del Caguán, Colombia. 1956-2016 (Tesis de maestría). Colegio de Michoacán. Centro de Estudios Rurales, Zamora, Michoacán.

Cumbre Agraria, Campesina Étnica y Popular, Marcha Patriótica e Indepaz. (23 de julio de 2019). Informe. Recuperado de http://www.indepaz.org.co/wpcontent/uploads/2019/07/Informe-parcial-Julio-26-2019.pdf

Cunill, Nuria. (1991). Participación Ciudadana. Dilemas y Perspectivas para la Democratización de los Estados Latinoamericanos. Caracas: Centro Latinoamericano de Administración para el Desarrollo.

Dejusticia. (22 de septiembre de 2020). Corte Suprema de Justicia protege el derecho a la protesta frente a la violencia policial. Recuperado de https:// www.dejusticia.org/corte-suprema-protege-el-derecho-a-la-protesta/

Fals Borda, Orlando. (Septiembre-diciembre de 1991). La accidentada marcha hacia la democracia participativa en Colombia. Análisis Político, (14), 4658. Recuperado de. https://revistas.unal.edu.co/index.php/anpol/article/ view/74677/67459 
Gobierno Nacional y Farc-Ep. (2017). Acuerdo Final para la Terminación del Conflicto y la Construcción de una Paz estable y duradera. Recuperado de http://www.altocomisionadoparalapaz.gov.co/herramientas/Documents/Acuerdo-Final-AF-web.pdf

Molano, Alfredo. (2015). Fragmentos de la historia del conflicto armado (19202010). En Eduardo Pizarro y Comisión Histórica del Conflicto y sus víctimas, Contribución al entendimiento del conflicto armado en Colombia (pp. 565-623). Bogotá: Ediciones Desde Abajo.

Mouffe, Chantal. (1999). El retorno de lo político. Comunidad, ciudadanía, pluralismo, democracia radical. Barcelona: Editorial Paidós.

Múnera, Leopoldo. (1999). Los estudios sobre la participación en Colombia. Recuperado de https://repositorio.unal.edu.co/handle/unal/75374

Nieto, Jaime. (2014). La participación como resistencia en el contexto del conflicto armado colombiano. Forum. Revista Departamento de Ciencia Política, 2(5), 139-159.

Retamozo, Martín y Stoessel, Soledad. (2014). El concepto de antagonismo en la teoría política. Estudios Políticos, 44, pp. 13-34. Recuperado de http://sedici.unlp.edu.ar/bitstream/handle/10915/36352/Documento_completo_. pdf? sequence $=1$ \&isAllowed $=y$

TeleSURtv. (15 febrero 2021). Son más de 20 líderes sociales asesinados en Colombia en 2021. Recuperado de https://www.telesurtv.net/news/colombia-lideres-sociales-asesinados-actualizacion-20210215-0054.html

Zubiría, Sergio de. (2015). Dimensiones políticas y culturales en el conflicto colombiano. En Eduardo Pizarro y Comisión Histórica del Conflicto y sus víctimas, Contribución al entendimiento del conflicto armado en Colombia. Bogotá: Ediciones Desde Abajo. 